\title{
Utilization of new Internet and broadband technologies in order to enhance the balanced development and to deal with the problem of "digital divide" of rural communities
}

\author{
C. Christodoulopoulou, J. Garofalakis, A. Koskeris \\ \& S. Michalopoulos \\ Research Academic Computer Technology Institute, Patras, Greece
}

\begin{abstract}
The Digital Divide problem can be described, in general, as the division of the world between those who have access to New Information and Communications Technology (ICT) applications and services and those who do not. This specific problem is particularly prevalent in rural and isolated territories in which the lack of ICT literacy and existing infrastructure leads to an increased digital divide. The presented work proposes an approach to support the solution of the problem of the digital divide within rural territories, using local "learning hubs" as a lever to enhance the use of new ICT. A specific methodology which will formulate a flexible, locally customizable tool that provides help in identifying all those parameters and issues that need to be taken into account when such an initiative sets out is presented, and specific outcomes of its application on several regions are given.

Keywords: digital divide, broadband, isolated areas, rural areas, learning hubs, ICT, regional development, information society, Internet access, telecenter.
\end{abstract}

\section{Introduction}

The presented work examines the ways in order to foster digital culture among rural citizens by demonstrating initiatives to bridge the digital divide through advanced broadband telecommunications providing remote areas with access to the Info-Society. Existing local establishments can be turned into local learning hubs, which provide the local labour force and citizens of all ages with fast 
Internet access and opportunities for lifelong learning creativity and development. Users are involved in the creation or adaptation of applications specifically addressing their own needs, so that users' perception of their problems leads the learning hub activity and not imposed solutions. Actual implementation is based on analyses of user needs, cost/benefit of technological options, compatibility with national strategies, and identified best practices. Through the presented work, local beneficiaries are discovering new opportunities for covering diverse needs and aspirations e.g. by selling their products and services over the web; by promoting their area as a tourist destination or as a site of cultural interest; or by exploiting rich lifelong learning resources available through the internet as students, employees or entrepreneurs. The learning hubs are acting as showcases and demonstrators of how modern ICT can be used for the development of similar "hubs" in any rural community, which will be able to maintain them without funding by sharing responsibility and imitative amongst local users. Thus a practical and easy to apply solution is offered to all remote rural communities in their struggle for equal opportunities for learning, economic and social development, and a more democratic access to the Info-Society.

\section{Digital divide and rural communities}

Within the last 10 years despite the spread of World Wide Web, the Internet has become one of the most valuable and effective communications media and the most inclusive source of information. However this "boom" has led to a new form of illiteracy, a "digital" one. Only those who can afford the PC and fast Internet connection are able to take advantage of it. By most counts, the number of PC and Internet users is very small compared to the numbers that would use it if they could. As more individuals are connected online, those who are not connected are increasingly in danger for becoming more marginalized within society. World widely there is a rising concern over the so-called "digital divide" - a term that refers to the gap existing in the opportunities to access advanced information and communication technologies between geographic areas or by individuals at different socio-economic levels [1,7-9].

The fact nowadays is that "The network society is creating parallel communications systems: one for those with income, education and literacy connections, giving plentiful information at low cost and high speed; the other are those without connections, blocked by high barriers of time, cost and uncertainty and dependent upon outdated information" [6].

The key factors leading to the digital divide are:

$\circ$ Missing infrastructure or access

- Missing incentives to use ICTs

- Lack of the computer literacy or skills necessary to take part in the information society

$\circ \quad$ Poverty and social exclusion

Most countries that have been concerned about this problem have instituted policies aimed at reducing aspects of it. For example, the EU launched the 
e-Europe initiative to accelerate the uptake of ICT across Europe and to ensure that all Europeans have the necessary skills to use them. E-Europe focuses on the social and regional aspects but also on technological aspects such as the provision of ICT services on multiple devices or platforms other than the PC (digital TV, satellite, third generation mobile phones, etc.) [11].

In reality there are several possible concrete cases of the digital divide gap occurrence [2]. One important subset of the digital divide issue concerns highspeed Internet access, also known as "broadband". Broadband refers to data transmission where multiple pieces of data are sent simultaneously to increase the effective rate of transmission, regardless of actual data rate. The "broadband divide" may be defined by those with rich, interactive audio and video services in the home and those with low-bandwidth, text-driven services. This divide will become increasingly important as the availability of advanced telecommunications become essential to the development of business, industry, shopping and trade, as well as distance learning, telemedicine, and telecommuting. The international digital divide also exists between different countries, with the ability of individuals to take advantage of the Internet varying significantly across the OECD area and between OECD and other countries. There are concerns that unless access to and use of the information and communication technology (ICT) is broadened, the majority of people, particularly in the developing countries, will not enjoy the benefits of the new knowledge-based economy. The Urban/rural divide refers to those set of people without an enhanced data capability which will lead them to be unable accessing the expected benefits particularly in relation to health and education. This concern is seen to be greatest in relation to those living and working in rural and remote areas since the lower rates for data access for these consumers place them at a disadvantage in comparison to metropolitan consumers. For these citizens the problems of missing infrastructures, incentives and computer literacy (the factors leading to Digital divide) are bigger and more difficult to solve. The world widely experience shows the several specialized initiatives needed for rural areas in order to anticipate expansion of current digital divide and at the same time provides solutions to deal with the actual problem.

In the USA several initiatives have been funded within the last years in order to deal with the digital divide problem in general and its' wide spread in rural communities in particular $[3,4]$. Some selected successful ones are presented below.

- The department of agriculture initiated a fund available for advanced telecommunications infrastructure in rural communities and the department of housing created an initiative to help establish computerlearning centres.

- The state of Illinois [11] utilized a legislation which makes it easier for technology providers to access grants from a specific Digital Divide Elimination Infrastructure Fund.

The Canadian government is also placing primary reliance on market forces while committing, "where market forces fail to provide a minimum level of 
access, to step in to ensure affordable access to essential services for all Canadians, regardless of their income or geographic location" [2].

Hong Kong uses the so-called Digital Solidarity fund (DSF) as an attempt to engage the government and the private sector as equal partners in tackling social problems [5].

In Europe [11, 2] several efforts have been given within the last years in the direction of dealing with the rural digital divide problem. The UK government's policy stance is typical in pronouncing a long-term strategy for developing Internet access, while placing primary reliance on market competition. Rapid rollout of high bandwidth communication networks, providing fast 'always-on' connections directly to business premises, homes and public access points in libraries and similar community institutions is a key objective of the Government. In Austria several initiatives aim to deal with the digital divide in any of its occurrences and types [10]. An example of an effective initiative especially for rural communities is the Lower Austria case which utilized the socalled "Infopoints" in each community and a "Service point" in each district head office to offer an easier access to information for citizens and tourists via Internet.

Most of the effective solutions presented above, focused directly on ensuring access to technology; the majority of access-based successful initiative also involved training. All these initiatives lead to the conclusion that in order to remain at the forefront of the Information Revolution, we need to:

- $\quad$ promote competition and a deregulatory environment in industries that deliver broadband services;

- maintain, and possibly expand, existing government grant and loan programs designed to assist the broadband build-out;

- increase investment in research and development in existing and alternative technologies;

- publish "best business practice" information to facilitate the sharing of ideas that work.

However, especially for the case of businesses and citizens in rural communities there is an additional need for the provision of cost-effective, reliable access to the information superhighway. Policymakers should consider new and creative ways to provide the following:

- connectivity: deliver broadband to the village;

- computer access: information appliance for use by illiterate people in rural communities;

- $\quad$ build digital literacy for the masses;

- content (provide digital libraries, eLearning tools, tele-medicine, easily searchable information).

The most important lesson is that there is an absolute necessity to work on, access, training, and contents at the same time to promote access to Internet. The experience is showing that in order to achieve these goals for rural communities we cannot based on households' infrastructures. Of course there is a need to work for achieving "broadband at home" but for the case of rural citizens, lacking on literacy and motivation, the first steps must be supported from the 
local public administration using its infrastructures and capabilities (see infopoints example in Austria). The presented work is giving a methodology on how to plan and organize such specialized support activities.

\section{An approach for the creation of telecenters in digitally disadvantaged rural areas}

Based on the outcomes derived from the above study, it is evident that in order to support effective use of new ICT from local rural communities we need a support mechanism managed from local forces (administration, business groups etc). In this chapter we present a methodology for the creation of such mechanisms (we call them "telecenters") in digitally disadvantaged and rural areas. We define as "telecenter" a place that enables and promotes the Information Society; uses and develops ICTs, and provides support services or advice to SMEs and the community; focuses on work-related activities and professional activities including services for social groups. This methodology is meant as a flexible, locally customizable tool that provides help in identifying all those parameters and issues that need to be taken into account when an initiative sets out to establish a local mechanism, aiming to address real local needs. All efforts to provide local Information Society solutions in rural areas need to take primarily into consideration the local perceptions of the needs of the community, as well as factual information about the local settings and conditions, which only members and/or collective bodies within the local community can provide validly. Therefore it is advisable to proceed with several steps which will all include the local community. The first step has to be the collection of needs and problems in relation with the use of new ICTs. The scope of this initial field work is to help identify the characteristics of the local rural territories, on the following sectors:

1.strategic background and community needs (administration model, relation with national and regional strategies, current useful services, potential useful services for the local groups);

2. economic situation (main economical activities and problems);

3. geographical description;

4. internet penetration (for business and at home);

5. additional problems (situation on computer literacy, and motivation on using new ICTs);

6. existing mechanisms to support the use of new ICTS in the territory (What kind, What they are offering, Problems, Positive impact).

Based on this initial work, the next step would be the identification of:

o where to create a telecenter in order to cover the needs and provide solutions;

$\circ$ by Whom and How (local force to operate it and how will organize it).

In a next step it is important to run a small-scale survey, to ask the local community, possibly through the completion of a questionnaire by an informed local agent (or more than one, if appropriate), about issues such as the following: 
Target group(s) and useful services.

The main principal is to address potentially all citizens of the remote area, without exclusions or discriminations by taking into consideration criteria such as geographical disadvantage, remoteness, and digital exclusion. For each of the chosen groups of users, the local informant should give a description concerning their current problems which can be solved, and needs which can be covered. It is also necessary to take into account any local sensitivity to certain issues, which could have an impact on the successful deployment of e-services and applications in the telecenter.

Existing premises and equipment that could be used for the telecenter.

One of the major issues for the establishment of a telecenter is the identification of the appropriate place for it. RACTI's methodology lies on the principal that the telecenters in rural areas do not need new buildings, as already existing local entities can host such new developments. Therefore, an issue of priority is to locate and describe existing premises within the area in which the telecenter is to be established, which could be used for this purpose. It is also advisable to think of all possible existing equipment which they think could be used. A list of equipment should be compiled, with as a detailed description of specifications as possible. Possible needs for upgrades to the existing equipment should also be recorded.

Local structures which can operate and / or support the telecenter.

The success or not will greatly depend on local organisations and institutions in the area of the planned telecenter that may be interested in using and/or supporting the telecenter.

Existing broadband connectivity.

For the different Internet connection technologies, such as DSL, wireless, satellite, etc., a clear understanding should be established of issues such as availability of the technology in the area of the telecenter, the extent of its use, its costs, average waiting time and cost for its installation.

Establishment plan and actual establishment.

The information on all the above issues that will be gathered needs to be considered and analysed coherently, leading to an informed decision of the kind of telecenter that should be established in this specific area, the services to be offered, the needed infrastructure, the appropriate time and synergies for its creation, as well as to an overall initial estimation of actions to be taken and their timing.

\section{Application of the methodology}

In the following paragraphs we briefly present the case of three territories in which we test the methodology (under the framework of an Interreg IIB CADSES project named: "Teleaccess"). These territories include isolated rural areas with strong digital divide problem occurrence and low level of computer literacy and new technologies use motivation, therefore the utilization of "telecenters" was decided as useful for the initial "push". Each case was different and leaded to different results after the application of the methodology. 


\subsection{The case of Dymi}

The first case involves a rural Municipal area in Western Greece, called Dymi. The initial field work lead to the following conclusions concerning its basic characteristics. Municipality of DYMI is a Local Government which belongs to the Region of Western Greece. In order to deal with the current Digital Divide problem the municipality is based on the national strategy for the Information Society. However, the effective application of new ICT in Dymi has been slow because of the lack of cooperation between the state, the private sector and the citizens and the lack of strong motivation for the local people. The farmers/grangers, the small and media merchants/entrepreneurs and the hotel owners are the major professionals. So much of the Primary sector (agriculture) along with the Tertiary sector (Tourism) are unfortunately not in prosperity the last years. Although Internet access and basic e-services are accepted as very useful for the local development, the outcomes until now are not satisfying. The Internet penetration is very low, especially in the distant rural areas, the computer skills are less than basic and the majority of Internet users have low connection.

The municipality administration has identified that the establishment of a telecenter will contribute positively to the bluntness of the digital "divide problem". Until now there are no telecenters existing in the territory, focused in distant rural businesses (which are the ones lacking much more behind). The only related info-centers are private owned training centers and public e-services offices. All these are very much specialized and not focused on the problems of local rural businesses. Based on the above outcomes of the initial research work, the municipality took the decision to establish a telecenter within an ex-school structure in a distant village of the municipality. In that way it will be possible to cover the needs of spread users and enhance their computer literacy providing them with an opportunity to get in touch with new technologies applications and services. From that point, a second detailed study carried out in order to:

- produce conclusions on which services will have to be delivered and for which target groups;

- fully specify the current infrastructure situation and the additional needs in order to effectively operate the telecenter.

The user groups that identified as the ones lagging more behind, and their specific needs in relation with new ICTs effective use were as follows.

1. Tourists: There are no info points to help them access information. A telecenter can give them such opportunity;

2. Farmers: Cultivators and graziers are not having access to Internet;

3. Women: Disadvantaged groups in a bad economic situation which need to find new opportunities.

\subsection{The case of Umbria and Marche}

The second case involved the regional area of Umbria in Italy. It is administered by a regional government, including several municipal rural areas. Its economy is based on four strong lines: manufacturing, handicrafts, agricultural, and 
tourism. Weakness points are the deficiency of infrastructures, the disequilibria related to geographical characters, social economy and environment. Positive elements can have an effect on the region, such as an uncontaminated environment, a cultural heritage as basis for tourism, social cohesion: an almost good quality of life, which can become unsustainable, without the development of new ICT. The decision of the regional government was to establish three telecenters in respective region's municipalities. These telecenters will act as innovation learning hubs to help the people from the nearby territories having an easy way to effectively use new technologies (which now are not used). Each one will focus on different target group and will provide different services based on the specific needs within each group. All of them will be established using of existing infrastructure of the respective municipalities, having the administrative support of the regional government. In another region of Italy with similar characteristics, called Marche, the methodology leaded to a different approach. It was found out that existing telecenters within the region act with efficiency and towards the right direction based on the identified needs. Therefore the decision was not to establish new telecenters but improve the already delivered services from the existing ones.

\subsection{The case of Haskovo}

The later case involves the Haskovo region in Bulgaria. Haskovo region is situated in central part of South Bulgaria. The population is 270096 people. $70.6 \%$ of the population live in cities and $29.4 \%$ in the villages. Geographically the region covers parts of the Upper Thracian Lowlands and parts of the Eastern Rhodopes. The regional Internet penetration is satisfying but the fast connection on WWW is very much lacking behind and therefore there is no effective use of specialised new ICT applications. The digital divide is much stronger in the small settlements. The basic national initiative in order to deal with the problem ("e-Bulgaria") unites all national programmes and projects in the area of ICT. Coordination for the implementation until now is not efficient therefore the region has decided to utilize 2 telecenters in order to help specific small municipalities with increased Digital Divide situation.

Mineralni bani is a rural municipality with population is 7000 people who are employed in agriculture, light industry and tourism. On the territory of the municipality there are no big industrial enterprises, which is one of the reasons for the high rate of unemployment. Stambolovo Municipality is a rural municipality with most of its settlements having population under 300 people. For the last few years there has been an intensive migration. The economy of the municipality is concentrated mainly in the municipal center. The communication services are limited. Existing telecenters within Haskovo are until now very few, public owned, situated in the capital and other big cities of the region, and they provide a very limited set of services. The additional ones which will be established within Mineralni and Stambolovo will focus on local businessmen and they will provide specialized e-services and consultancy/training on ICT. 
The further contribution of the two additional telecentres to the development of the region will be sought in several directions:

- economic impact (percentage of (youth) employment; percentage of successful job searches, household engaged in small enterprises, increased number of markets for buying and selling);

- social impact (percentage of specialists residing in the community, opportunities for distance and life-long learning);

- Impact on local organizations (networking, sharing information with similar organizations, participation in discussion groups).

\section{Conclusions and further work}

As mentioned earlier within this paper, the key factors leading to the digital divide are: Missing infrastructure or access, Missing incentives to use ICTs, Lack of the computer literacy or skills, Poverty and social exclusion. These barriers are very difficult to overcome within rural territories (especially distant isolated ones) and therefore the solution for these cases must include apart from traditional efforts (establish the needed infrastructure and provide financial help in order to have access) some additional support ones from the local actors (administrations, business chambers etc). The experience until now showed that a helpful initiative towards this direction can be the creation of local "learning hub" (telecenters) which will act as a lever to promote and support the use of information society from all local people within a rural territory (which normally lack motivation and opportunities to acquire it).

However, this establishment of telecenters is not effective by its own. It has to be supported and sustained actively by local stakeholders and it has also to be based on the actual local needs and situation. With the current work we propose a methodology in order to created telecenters fully customised based on the specific economic situation, existing barriers and problems, and local users needs. We presented the steps of the application of this methodology in several local rural communities in Greece, Italy and Bulgaria in order to establish local telecenters and how this leaded to different solutions (different kind of telecenters, by different kind of local stakeholders, providing different services to several local groups). The next step of the work will include three different directions. Firstly we plan to organize additional application on several other territories (in Western Greece, Poland, and Former East Germany). Secondly we will test the methodology on isolated islands areas (which are facing similar digital divide problem as rural ones). Finally the next step will be the assessment of telecenters operation results and how these are connected with the results of the methodology (with a final aim to create a second version of it dealing with the problems arisen after telecenters operation).

\section{References}

[1] Brachos, A., Kostopoulos, K.C., Soderquist, K.E., Digital Divide and the Future of the 'Information Society, IFIP International Conference for the 
Information Systems Perspectives and Challenges in the Context of Globalization: Athens, Greece, 2003

[2] Bridging the "Digital Divide": Issues and Policies in OECD Countries, Organisation for Economic Co-operation and Development, Jul 2001, http://www.oecd.org/dataoecd/10/0/27128723.pdf.

[3] Closing the Digital Divide in Rural Communities: National Governors Association Committee on Economic Development \& Commerce, USA, $2001 \quad$ online. http://www.bcnet.org/Broadband/FixedWirelessBroadbandProject.nsf

[4] Courtright, C., Robbin, A., Deconstructing the Digital Divide in the United States: An Interpretive Policy Analytic Perspective, International Association of Media and Communication Research, Austin, Texas, USA, 2001

[5] Fung, Y., J., The Digital Divide and the role of NGOs in empowerment of disadvantaged groups via ICT in Hong Kong, eds: UNCRD and UNDP, USA, 2006

[6] Globalization with a Human Face, United Nations Development Programme UNDP, Human Development Report (Chapter Two): New technologies and the global race for knowledge, 1999.Online. http://hdr.undp.org/reports/global/1999/en/pdf/hdr_1999_ch2.pdf

[7] Improving IT connectivity in the Least Developed Countries: International Telecommunication Union, Online. http://www.itu.int/aboutitu/index.html

[8] Reddy, R., A., Multifunction Information Appliance for Emerging Economies, Mythology and Reality of the Digital Divide Problem, Presented at MIT Quanta Conference: Pittsburgh, USA, 2005

[9] Schloman, F.B., The Digital Divide: How Wide And How Deep? Journal of Issues in Nursing, 2004

[10] The Digital Divide in Austria, Institute of Technology Assessment, Austrian Academy of sciences, Country Report, Conference 'Stepping Stones Into The Digital World', Bremen, Germany, 2000

[11] Xavier, P., Bridging the "Digital Divide": Issues and Policies in OECD Countries, Organisation for Economic Co-operation and Development, declassified by Committee For Information, Computer And Communications Policy at its meeting of 22-23 February, 2001 